Review

\title{
Efficacy of low-dose rituximab for the treatment of mixed cryoglobulinemia vasculitis: Phase II clinical trial and systematic review
}

\author{
Marcella Visentini ${ }^{\mathrm{a}, *}$, Carmine Tinelli ${ }^{\mathrm{b}}$, Stefania Colantuono ${ }^{\mathrm{a}}$, Monica Monti ${ }^{\mathrm{c}}$, Serena Ludovisi ${ }^{\mathrm{d}}$, \\ Laura Gragnani ${ }^{\mathrm{c}}$, Milica Mitrevski ${ }^{\mathrm{a}}$, Jessica Ranieri ${ }^{\mathrm{c}}$, Elisa Fognani ${ }^{\mathrm{c}}$, Alessia Piluso ${ }^{\mathrm{c}}$, Massimo Granata $^{\mathrm{a}}$, \\ Annalisa De Silvestri ${ }^{\text {b }}$, Valeria Scotti ${ }^{\text {}}$, Mario U. Mondelli ${ }^{d}$, Anna Linda Zignego ${ }^{c}$, \\ Massimo Fiorilli ${ }^{\text {a }}$, Milvia Casato ${ }^{\mathrm{a}}$ \\ a Department of Clinical Medicine, Sapienza University of Rome, Rome, Italy \\ b Clinical Epidemiology and Biometric Unit, IRCCS Policlinico S. Matteo Foundation, Pavia, Italy \\ ${ }^{c}$ Research Center for Systemic Manifestations of Hepatitis Viruses, Department of Internal Medicine, University of Firenze, Firenze, Italy \\ d Infectious Diseases Research Laboratories, IRCCS Policlinico S. Matteo Foundation, Pavia, Italy
}

\section{A R T I C L E I N F O}

\section{Article history:}

Received 15 May 2015

Accepted 24 May 2015

Available online 29 May 2015

\section{Keywords:}

Mixed cryoglobulinemia

Rituximab

Low-dose

\begin{abstract}
A B S T R A C T
Objective: To evaluate whether rituximab at a low dose of $250 \mathrm{mg} / \mathrm{m}^{2} \times 2$ may be as effective as at higher dosages, most commonly $375 \mathrm{mg} / \mathrm{m}^{2} \times 4$, used in previous studies on the treatment of patients with refractory mixed cryoglobulinemia (MC) vasculitis associated with hepatitis $\mathrm{C}$ virus (HCV) infection.

Methods: We conducted a phase 2, single-arm two-stage trial (EUDRACT n. 2008-000086-38) of low-dose rituximab in 52 patients with HCV-associated MC who were ineligible/intolerant or non-responder to antiviral therapy. The primary outcomes were response of vasculitis evaluated by the Birmingham Vasculitis Activity Score (BVAS) at months 3, 6 and 12, rate of relapses and time to relapse, and rate of adverse events. Our data were compared with those reported in 19 published studies selected among 291 reviewed in a literature search. Results: The cumulative response rate (complete and partial) at month 3 was $81 \%$ in our patients, and $86 \%$ in 208 patients from studies using high-dose rituximab. The relapse rate and median time to relapse were, respectively, $41 \%$ and 6 months in our study, and 32\% and 7 months in high-dose studies. Treatment-related adverse events were $11.5 \%$ in our study and $19.9 \%$ in high-dose studies. None of these differences was statistically significant. Conclusion: Rituximab at a low dosage of $250 \mathrm{mg} / \mathrm{m}^{2} \times 2$ is as effective as at higher dosages for treating MC vasculitis. This low-dose regimen may improve the cost/benefit profile of rituximab therapy for MC.
\end{abstract}

(c) 2015 Elsevier B.V. All rights reserved.

Contents

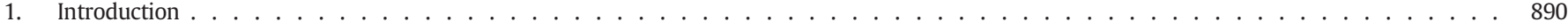

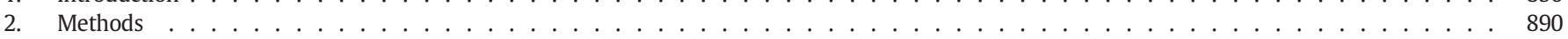

2.1. Study design . . . . . . . . . . . . . . . . . . . . . . . . . . . . . . . . . 890

2.2. Sample size determination and stopping rules $\ldots \ldots \ldots$

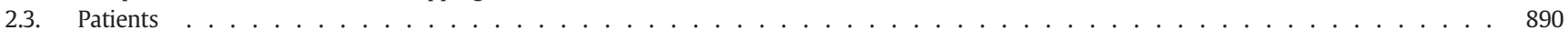

2.4. Efficacy assessment $\ldots \ldots \ldots$

2.5. Laboratory data . . . . . . . . . . . . . . . . . . . . . . . . . . . . . . . . . 891

2.6. Systematic review of the literature . . . . . . . . . . . . . . . . . . . . . . . . . . . . . . . . 891

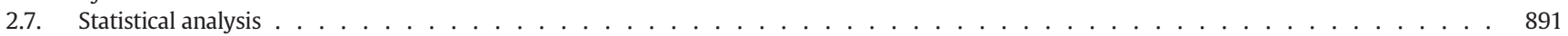

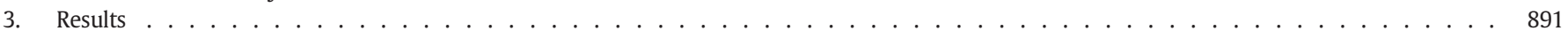

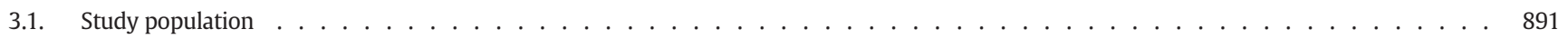

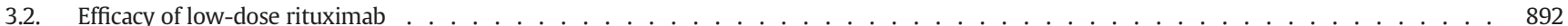

3.2.1. Clinical efficacy . . . . . . . . . . . . . . . . . . . . . . . . . . . . . . . . . . . . . . . . . . . . 892

3.2.2. Laboratory efficacy . . . . . . . . . . . . . . . . . . . . . . . . . . . . . . . . .

Abbreviations: MC, mixed cryoglobulinemia; HCV, hepatitis C virus; SMZL, splenic marginal zone lymphoma; SVR, sustained virological response; PEG-IFN, pegylated interferon alpha; DAA, direct-acting antiviral; BVAS, Birmingham Vasculitis Activity Score; CR, complete response; PR, partial response.

* Corresponding author at: Department of Clinical Medicine, Sapienza University of Rome, Viale dell'Universittà 37, 00185 Rome, Italy. Tel.: + 390649972036 ; fax: + 39064440806. E-mail address: marcella.visentini@uniroma1.it (M. Visentini). 


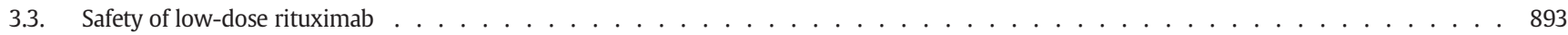

3.4. Comparison of efficacy and safety of low-dose vs high dose rituximab $\ldots \ldots \ldots$

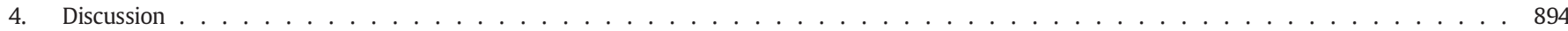

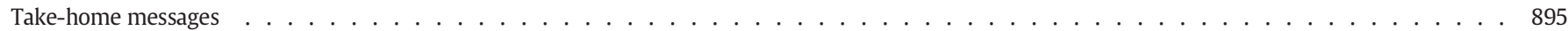

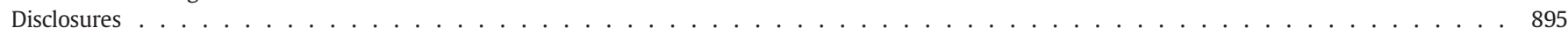

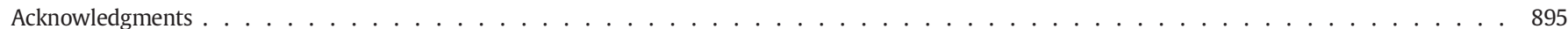

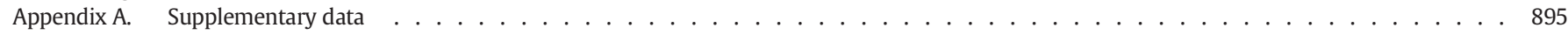

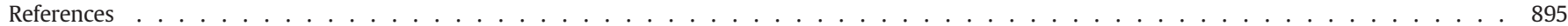

\section{Introduction}

Type II mixed cryoglobulinemia (MC) is a systemic vasculitis caused by immune complexes formed by monoclonal IgM rheumatoid factor and polyclonal $\operatorname{IgG}$, which precipitate at $t^{\circ}$ less than $37^{\circ}$ and cause small vessel vasculitis [1]. It is currently considered a rare disease, although the prevalence of the vasculitis presents geographical differences, in relation to HCV infection prevalence [2]. Indeed in more than $90 \%$ of cases MC is secondary to hepatitis C virus (HCV) infection, which determines chronic stimulation and benign monoclonal expansion of B-cells producing a natural poly (auto)-reactive IgM antibody. These B cells proliferate very poorly [3], and this may explain why immunosuppressive and cytotoxic drugs are scarcely effective in MC. Over time, chronic stimulation of B-cells by HCV may give rise to genetic changes and evolution to overt lymphoma, typically splenic marginal zone lymphoma (SMZL) [4], that may regress after eradication of HCV with antiviral therapy $[5,6]$.

The most frequent manifestations of MC are cutaneous leucocytoclastic vasculitis leading to purpura and skin ulceration, peripheral neuropathy, glomerulonephritis [1] and central nervous system vascular lesions that may underlie cognitive impairment [7]. In some patients, MC has an acute onset and presents a life-threatening course with skin ulcers, renal involvement and abdominal vasculitis [8].

$\mathrm{HCV}$ clearance with sustained virological response (SVR) is the main goal in the treatment of patients with HCV-associated MC, and leads to remission of vasculitis and reduced mortality $[8,9]$. So far, the best combination for achieving HCV eradication in MC patients is with pegylated interferon alpha (PEG-IFN) and ribavirin [9]. Unfortunately, many patients are ineligible/intolerant, fail to respond or relapse after initial response to this regimen; these patients may have a grim prognosis and bear high health care costs [10].

New direct-acting antiviral (DAA) agents yielding 90-100\% SVR rates [11] may change this scenario, and clinical trials with IFN-free regimens for $\mathrm{HCV}$-associated cryoglobulinemia are eagerly awaited [12].

Starting 15 years ago, a number of studies (open studies and case reports) have demonstrated that the anti-CD20 chimeric monoclonal antibody rituximab is highly effective for the treatment of HCVassociated MC, refractory or intolerant to antiviral therapy [13-31]. Only recently, two randomized controlled trials $[29,30]$ showed that rituximab is largely superior to conventional immunosuppressive drugs for treating cryoglobulinemic vasculitis, providing further evidence of its clinical efficacy and safety in this setting. The rituximab dosage used in nearly all published reports was $375 \mathrm{mg} / \mathrm{m}^{2}$ given four times, the treatment schedule used for B cell NHL [13,14,16-20,22-28, 30]. Other studies used the dosage of $1000 \mathrm{mg}$ for two administrations, as for the treatment of rheumatoid arthritis [22,27,29,31] and only few patients were treated with the higher dosage of $375 \mathrm{mg} / \mathrm{m}^{2}$ for four administrations plus two monthly maintenance dosages [15,18,21,27]. However, the issue of optimal dosing of rituximab for treating MC has not been addressed so far.

Low-dose regimens of rituximab have been shown to be efficacious in different immunological disorders such as rheumatoid arthritis [32-34], systemic lupus erythematosus [35,36], autoimmune haemolytic anemia [37], immune thrombocytopenia [38], pemphigus [39] and myasthenia gravis [40]. Remarkably, a recent meta-analysis [41] demonstrated that low-dose rituximab $(500 \mathrm{mg} \times 2$ ) has similar effectiveness and meets non-inferiority criteria compared to the licensed dose of $1000 \mathrm{mg} \times 2$ for the treatment of rheumatoid arthritis.

Based on a pilot study in 6 patients [42], we designed a phase II, single-arm two-stage multicenter study to evaluate the efficacy of low-dose rituximab $\left(250 \mathrm{mg} / \mathrm{m}^{2}\right.$ given twice one week apart) in patients with refractory HCV-associated mixed cryoglobulinemia. The mid-term results in 27 of the 52 patients to be enrolled in this study were published in 2011 [43]. Here we report the final results of the study, providing confirmatory evidence of equal efficacy of low-dose compared to high-dose rituximab for the treatment of patients with $\mathrm{HCV}$-associated MC who are ineligible/intolerant or unresponsive to antiviral therapy.

\section{Methods}

\subsection{Study design}

This phase 2, single-arm, two-stage multicenter study (EUDRACT $\mathrm{n}$. 2008-000086-38), aimed at assessing the efficacy/safety profile of lowdose rituximab for refractory mixed cryoglobulinemia, was conducted in three university centers (Sapienza University of Rome, University of Florence and University of Pavia). The study was approved by the Internal Review Boards of all participating institutions, and written informed consent was obtained from each patient according to the ethical guidelines of the Declaration of Helsinki.

\subsection{Sample size determination and stopping rules}

Sample size estimate was performed using the Simon's optimal twostage procedure. Based on prior data [43], the estimated percentage of patients reaching a $50 \%$ reduction of the Birmingham Vasculitis Activity Score (BVAS) and of cryocrit was $40-60 \%$ after $10-12$ weeks of treatment (primary objective). Fifty-two patients were planned to be treated; for $>27 / 52$ responders the conclusion would be that the investigational therapy is effective in these patients. The procedure described above tests the null hypothesis ( $\mathrm{Ho}$ ) that the true response rate is $60 \%$ versus the alternative hypothesis $(\mathrm{Ha})$ that the true response rate is at least $40 \%$. The level of significance (i.e., the probability of rejecting the Ho when it is true) is 0.03 ; the power (i.e., the probability of rejecting the Ha when it is true) is 0.85 .

Interim analysis of the results, made by the IDSMB, involved 16 patients entered into the first stage of the study. For $<5 / 16$ patients responding to investigational therapy at week 12 , the study would be stopped on the basis of the assumption that the drug is not active in this subset of patients. Supplementary Table 1 summarizes the characteristics of the study design.

\subsection{Patients}

Fifty-two consecutive, unselected patients were enrolled in the study. Requirements for enrolment were: diagnosis of mixed cryoglobulinemia (type II or III) evidenced by at least one of the following manifestations: purpura, skin ulcers, peripheral neuropathy, renal, 
gastrointestinal, pulmonary or CNS involvement, or signs and symptoms of hyperviscosity; chronic HCV infection, with positive serology and/or HCV viremia. All patients had failed to respond to or had relapsed without indication to retreatment after standard-of-care anti-HCV therapy with Peg-IFN $\alpha$ plus ribavirin, or had contraindication or intolerance to treatment. Patients previously treated with rituximab were excluded. Other exclusion criteria were an age below eighteen, coexistence of lifethreatening condition(s) unrelated to MC, HIV infection, a diagnosis of hematological or non-hematological malignancy (excluding low-grade B-cell NHL), pregnancy or breast feeding, ongoing therapy with high dose corticosteroids and/or immunosuppressive drugs or plasmapheresis, and any ongoing infection. Patients were eligible after a 2-month washout from immunosuppressive therapy or plasmapheresis or after healing of infection(s). Low-dose steroids were permitted through the study. Patients with chronic hepatitis B infection were considered ineligible, whereas patients potentially at risk for reactivation of occult HBV (e.g., anti-HBc positive with negative anti-HBsAb, HBV viremia and $\mathrm{HBsAg}$ ) were considered eligible but were treated with 1-year lamivudine prophylaxis.

Patients were treated with rituximab $250 \mathrm{mg} / \mathrm{m}^{2}$, given twice at one-week interval after premedication with methylprednisolone $0.5-1 \mathrm{mg} / \mathrm{kg}$, paracetamol $1 \mathrm{~g}$ and chlorpheniramine $10 \mathrm{mg}$.

\subsection{Efficacy assessment}

Clinical and laboratory data were evaluated monthly for 12 months after treatment; the response rates were analyzed at months 3, 6, and 12. Clinical response to treatment was defined as follows: complete response $(\mathrm{CR})$ for $\mathrm{BVAS}=0$, and partial response $(\mathrm{PR})$ for $\mathrm{BVAS}<50 \%$ of the baseline. Primary endpoint of the study was the overall number of patients achieving a clinical response (complete or partial) at any time during the study. Laboratory response was defined as complete for disappearance of cryoglobulins, and partial for a decrease of cryocrit to less than $50 \%$ of baseline level.

Clinical relapse was defined as any increase in the BVAS score after response, and laboratory relapse as any increase in the cryocrit level after disappearance or significant reduction. When patients were considered non-responders or relapsers and required alternative therapies follow-up was stopped.

Adverse events were defined as certainly or possibly related to rituximab based on the following criteria: a) interval of time between drug administration and event; b) disappearance of the event after drug infusion interruption; and c) specific adverse events clearly known as dependent on rituximab.

Severe adverse events were considered as grade 4 and grade 5 , according to the DAIDS Adverse Event Severity Grading tables (Division of AIDS, Table for Grading the Severity of Adult and Pediatric Adverse Events, Version 1.0, December 2004; Clarification August 2009 (online at http://rsc.tech-res.com)).

\subsection{Laboratory data}

All blood samples were drawn with pre-warmed syringes and tubes, allowed to clot and centrifuged at $37^{\circ} \mathrm{C}$ for serum separation, according to previously published recommendations [44]. Sera were kept at $4{ }^{\circ} \mathrm{C}$ for 7 days and cryocrit was expressed as the percentage of serum volume after centrifugation. The number of circulating B-cells was measured by four-color flow cytometry in fresh blood samples using antibodies to CD19, CD20, kappa- and lambda-chain fluorochromeconjugated antibodies (Becton Dickinson). B cell depletion was defined as a value of circulating B cells $\leq 5 / \mu$ l. Serum HCV RNA was measured by the Amplicor HCV assay (Roche Diagnostics). Blood samples were processed at rigorously controlled temperature, as previously described [45], to avoid the co-precipitation of virions with cryoglobulins.

\subsection{Systematic review of the literature}

A systematic search of the medical literature was performed in the last week of November 2014. The search was constructed and performed by an experienced librarian using Pubmed, Embase and Web of Science. The following search strategy was used: (cryoglobulinemia OR "cryoglobulinemic vasculitis") AND (rituximab OR anti-CD20). There were language restrictions (English, French, Spanish, Italian).

We retrieved 423 references, from which 126 duplicates were eliminated and the remaining 297 records were screened; 31 studies were retrieved as full-text, and 19 were selected for qualitative analysis [13-31]. No quantitative comparison was possible since 17 of these 19 studies were single-arm and only two $[29,30]$ were randomized controlled trials; however cumulative prevalence of responders was evaluated.

\subsection{Statistical analysis}

Categorical variables are expressed as count and percentages, quantitative ones as mean and standard deviation (sd) or median and interquartile range (IQR), as appropriate.

Categorical variables were compared with Fisher's exact test.

Analysis of variance for repeated measures models were fitted to evaluate changes in BVAS over time, also taking into account cryocrit as a covariate; univariate logistic regression models with outcome of therapy as response variable were fitted to evaluate the effect of single demographic, clinical or laboratory variables at baseline on clinical or laboratory response. Univariate Cox regression models were fitted with sex, age, disease duration, specific vasculitis manifestations, BVAS value, cryocrit, HCV viremia, B-cell count or occurrence of adverse events as independent variables and presence of relapse as response variable.

Cumulative prevalence of responders to high dose treatment is calculated across selected studies and presented with binomial exact 95\% confidence interval. Time to relapse is shown by a Kaplan-Meier curve and compared between high and low dose treatments with log-rank test.

\section{Results}

\subsection{Study population}

The characteristics of the study population are illustrated in Table 1. All patients had at least one of the following manifestations: purpura,

Table 1

Baseline demographic and clinical characteristics of the 52 study patients.

\begin{tabular}{|c|c|}
\hline Variable $^{\mathrm{a}}$ & Value \\
\hline Female sex, $\mathrm{n}$ of patients (\%) & $40(77 \%)$ \\
\hline Disease duration (months), median (IQR) & $48(16-108)$ \\
\hline Age (years), mean $( \pm S D)$ & $69( \pm 8.4)$ \\
\hline BVAS value, mean $( \pm S D)$ & $13( \pm 6.4)$ \\
\hline \multicolumn{2}{|l|}{ Manifestations of vasculitis, n of patients (\%) } \\
\hline Purpura & $45(87 \%)$ \\
\hline Skin ulcers & $14(27 \%)$ \\
\hline Neuropathy & $47(90 \%)$ \\
\hline Nephropathy & $22(42 \%)$ \\
\hline Arthralgia & $39(75 \%)$ \\
\hline Cirrhosis, $\mathrm{n}$ of patients $(\%)$ & $15(29 \%)$ \\
\hline Cryocrit (percent), median (IQR) & $5(3-9)$ \\
\hline HCV load $\left(\log _{10}\right.$ copies $\left./ \mathrm{ml}\right)$, mean $( \pm \mathrm{SD})$ & $5.32( \pm 2.2)$ \\
\hline \multicolumn{2}{|l|}{ HCV genotype, $n$ of patients (\%) } \\
\hline 1 & $18(59 \%)$ \\
\hline 2 & $13(38 \%)$ \\
\hline 4 & $1(2 \%)$ \\
\hline ALT (IU/ml), median (IQR) & $32(16-57.6)$ \\
\hline B cell count (cells/ $\mu \mathrm{l})$, median (IQR) & $138(86-255)$ \\
\hline
\end{tabular}


peripheral neuropathy, skin ulcers or kidney disease. Both mild/ moderate and severe forms of cryoglobulinemic vasculitis, e.g., neuropathy and/or purpura vs severe skin ulcers and kidney disease [10], were represented in the study cohort. All patients had anti-HCV antibodies, but in 4 cases serum HCV RNA was repeatedly undetectable.

\subsection{Efficacy of low-dose rituximab}

\subsubsection{Clinical efficacy}

Supplementary Fig. 1 denotes patients' disposition through the study. Fifty-two patients were accrued, and efficacy assessment was done at months 3, 6 and 12. Four patients were not evaluable because they did not reach the month 3 endpoint; one had a severe adverse event precluding treatment, one died of myocardial infarction unrelated to treatment, and two were lost to follow-up. Nine patients failed to reach month 12; four of them died and five were lost to follow-up. An additional patient died while in remission at month 12, and was therefore recorded as in remission at that time point.

The primary endpoint of the study was the number of patients achieving at any time after treatment a complete (BVAS $=0$ ) or a partial (reduction of BVAS of at least $50 \%$ of baseline) clinical response. Thirtynine of $48(81 \%)$ evaluable patients achieved a clinical response at month 3 (Table 2), and two responded after month 3 bringing the overall response rate to 85\%; no responses after month 6 were recorded. At month 12, 17 patients remained in remission whereas 17 had relapsed (Supplementary Fig. 1).

Interestingly, treatment appeared to be of benefit also to formally non-responding patients, since in this group the BVAS decreased significantly ( $\mathrm{p}=0.009$ ) by month 6 although not reaching the primary endpoint of $>50 \%$ abatement.

No single demographic, clinical or laboratory variable at baseline affected the outcome of therapy. However, the baseline BVAS tended to be lower in non-responders than in responders $(11.2 \pm 3.8 \mathrm{vs}$ $14.2 \pm 6.6 ; \mathrm{p}=0.2$ ).

Overall, 41 of 48 evaluable patients (85\%) achieved a clinical response throughout the study. The median time to remission/ improvement of vasculitis was one month (range 1-4 months). Seventeen of 41 responders ( $41 \%$ ) experienced a relapse of vasculitis during a 1-year FU, with a median time of 6 months (range 4-12 months) (Fig. 1). Eleven of 45 (24\%) evaluable patients relapsed before month 6 , and 6 of 41 patients relapsed between month 6 and month 12 . None of the variables tested by univariate analyses (sex, age, disease duration, specific vasculitis manifestations, BVAS value, cryocrit, HCV

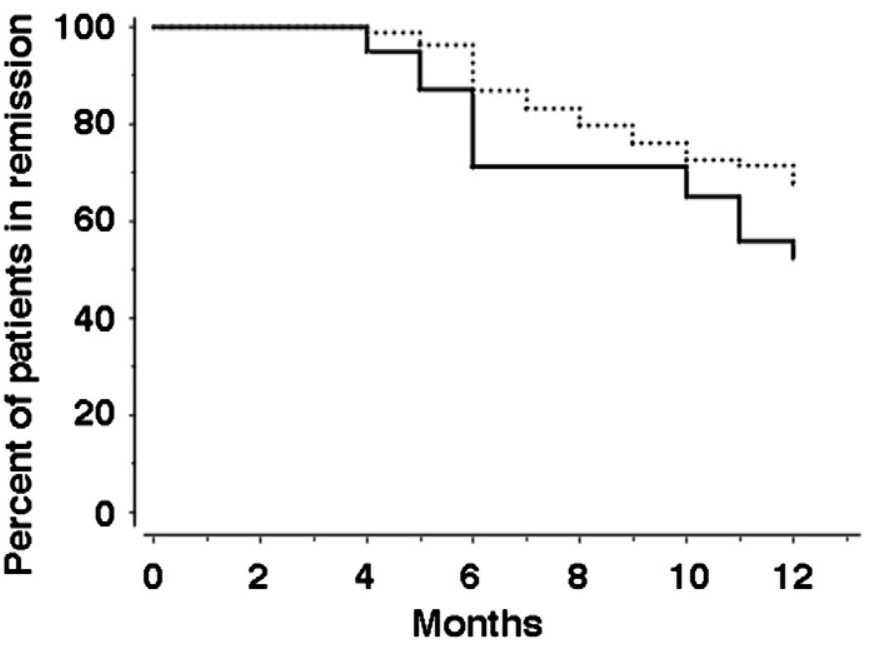

Fig. 1. Kaplan-Meier curve of the duration of remission in patients responding to low-dose ( $n=41$, solid line) or high-dose $(n=84$, dotted line) rituximab.

viremia, B-cell count or occurrence of adverse events) was significantly associated with an increased risk of relapse.

\subsubsection{Laboratory efficacy}

Complete laboratory response was defined as the complete disappearance of cryoglobulins in the serum and a partial response as a reduction of cryocrit to less than $50 \%$ of the baseline. A laboratory response was achieved in $54 \%$ of patients throughout the study, with a complete response in $44 \%(21 / 48)$ and a partial response in $10 \%(5 / 48)$ (Table 2). Decline of cryocrit after rituximab was quite slow, as also reported previously [14]. In fact, at month 3 post-therapy only $27 \%$ of patients had cleared cryoglobulins and $19 \%$ had $>50 \%$ reduction. Eight of 26 laboratory responders had relapsed (any increase of cryocrit) by month 12 ; five of these patients also presented a clinical relapse.

One month after the second infusion of rituximab all patients, except one who did not receive full treatment because of a severe adverse event during the first infusion, showed a complete B-cell depletion in peripheral blood. B-cells repopulated (>5 B-cells/ $\mu \mathrm{l})$ in 33\% (16/48) of patients at month 3 , and in $69 \%$ of evaluable patients at month 6 ; at month 12 only one patient, a complete clinical responder, was still B-cell depleted. No association of B-cell depletion with clinical response

Table 2

Comparison of the efficacy and safety of low-dose (present study) and high-dose (studies from the indicated references) rituximab therapy for MC vasculitis

\begin{tabular}{|c|c|c|c|c|}
\hline Variable & Low-dose $^{\mathrm{a}}$ & High-dose $^{a}$ & p-Value ${ }^{a}$ & Ref. \\
\hline \multicolumn{5}{|l|}{ Clinical response $^{\mathrm{b}}$} \\
\hline Patients evaluable & 48 & 208 & & $13-17,19-21,23-26,28-30$ \\
\hline Complete response & $24(50 \%)$ & & & \\
\hline Partial response & $15(31 \%)$ & & & \\
\hline Total response & $39(81 \%)$ & $178(86 \%)$ & 0.50 & \\
\hline \multicolumn{5}{|l|}{ Laboratory response } \\
\hline Patients evaluable & 48 & 202 & & $13-15,7,19,21,23-25,27,28$ \\
\hline Complete response & $21(44 \%)$ & $83(41 \%)$ & 0.43 & \\
\hline Partial response & $5(10 \%)$ & $43(21 \%)$ & 0.15 & \\
\hline Total response & $26(54 \%)$ & $126(62 \%)$ & 0.41 & \\
\hline \multicolumn{5}{|l|}{ Relapse rate (mo 12) } \\
\hline Patients evaluable & 41 & 84 & & $13,14,17,24,29,30$ \\
\hline Relapsers & $17(41 \%)$ & $27(32 \%)$ & 0.32 & \\
\hline Median TTR (range) ${ }^{\mathrm{b}}$ & $6(4-12)$ & $7(4-12)$ & 0.67 & \\
\hline \multicolumn{5}{|l|}{ Adverse events } \\
\hline Patients evaluable & 52 & 371 & & $13-15,17-19,21-27,29,30$ \\
\hline Total adverse events & $6(11.5 \%)$ & $74(19.9 \%)$ & 0.13 & \\
\hline Severe adverse events & $1(1.9 \%)$ & $22(5.9 \%)$ & 0.34 & \\
\hline
\end{tabular}

\footnotetext{
a Data refer to the number of patients (percentages), unless otherwise denoted. Data in high-dose patients were obtained from the indicated references. The p-values were calculated by Fisher's exact test. SD: standard deviation; TTR: time to relapse.

b Comparisons of complete and partial clinical responses are not shown because data were inadequately reported in several literature studies.
} 
Table 3

Adverse events in 52 patients treated with low-dose rituximab.

\begin{tabular}{ll}
\hline Adverse events & N of patients \\
\hline Total & 6 \\
Severe & 1 \\
Anaphylaxis & 1 \\
Mild/moderate & 5 \\
Serum sickness syndrome & $2^{\mathrm{a}}$ \\
Flu-like syndrome & 1 \\
Late-onset neutropenia & 1 \\
Thrombophlebitis of the leg & 1 \\
Infectious & 1 \\
Legionellosis & $1^{\text {a }}$ \\
\hline a One patient had serum sickness and legionellosis in two separate episodes.
\end{tabular}

or with cryocrit level was found. By contrast, a significant correlation between baseline cryocrit level and BVAS at any time-point ( $p=0.003$ ), and between cryocrit level and decrease in BVAS over one-year follow-up was observed $(\mathrm{p}=0.031)$.

\subsection{Safety of low-dose rituximab}

A total of 7 adverse events certainly or possibly related to treatment were recorded in 6 patients (Table 3). An 80-y old female experienced severe anaphylaxis (itching, skin rash, bronchospasm, wheezing) immediately after starting her first infusion of rituximab; symptoms resolved after interruption of infusion and administration of antihistamine and steroids. This patient was not treated further with rituximab. Six mild/moderate adverse events occurred in five patients and were considered possibly caused by rituximab. Two patients presented with serum sickness (urticaria and fever) about one week after the second infusion of rituximab; symptoms healed spontaneously in one case and after antihistamines and steroids in the other. One patient presented 3 months after rituximab with neutropenia (340 cells/ $\mu$ ), which resolved spontaneously in 2 weeks. One patient had at month 1 thrombophlebitis of the left leg, which resolved after nonsteroidal antiinflammatory drugs and low-molecular-weight heparin. One patient presented one week after the second rituximab infusion with a flu-like syndrome, consisting of severe arthralgia, nausea and vomiting. Finally, one patient, who also had developed serum sickness in a separate adverse episode, had Legionella pneumonia that healed upon antibiotic therapy.

Six deaths unrelated to adverse events occurred throughout the study. Three patients were responders: a 68-y old female died at month 6 of acute pulmonary oedema due to kidney and heart failure, and a 66-y old female at month 9 of heart failure. The third patient in this group, a 56-y old male, died at month 12 of pulmonary atypical mycobacterial infection and decompensated cirrhosis. The relation mycobacterial infection with rituximab therapy was considered unlikely, although two cases of severe infection by atypical mycobacteria have been described after combined treatment with rituximab and immunosuppressive drugs [46]. Two non-responders died at months 3 and 7 of complications of cryoglobulinemia, namely abdominal vasculitis and kidney and heart failure. One patient died of myocardial infarction at month 2, and her response could not be evaluated.

Finally, no significant changes of HCV viral load or of liver function parameters were observed after low-dose rituximab.

\subsection{Comparison of efficacy and safety of low-dose vs high dose rituximab}

Nineteen articles [13-31] out of 297 reports on high-dose (i.e., higher than $250 \mathrm{mg} / \mathrm{m}^{2} \times 2$ ) rituximab therapy for mixed cryoglobulinemia screened in a systematic review of the literature were selected for comparative purposes. Two studies were randomized controlled trials $[29,30]$, whereas all the others were uncontrolled studies including at least 2 patients. Collectively, these studies provided fruitful information in 359 patients, 26 of whom (7\%) had a diagnosis of NHL. These 359 patients were treated with rituximab with either of the following dosages: $1000 \mathrm{mg} \times 2$ (87 patients), $375 \mathrm{mg} / \mathrm{m}^{2} \times 4$ (236 patients), or $375 \mathrm{mg} / \mathrm{m}^{2} \times 6$ (36 patients) (Table 4 ).

The selected studies were very heterogeneous as to the methods and timing of efficacy assessment and to the scoring system, and validated BVAS was adopted only by the two randomized controlled trials [29, 30]. The time of efficacy assessment was, in most studies, at months 3 and 6 , and the follow-up ranged between 6 and 31 months. For comparing the results of these studies with our data, we either calculated the BVAS in trials in which adequate data were provided $[13,15,17,19$, $28,24]$, or adopted the definition of response used by the authors.

Table 2 summarizes a comparison of the efficacy and safety profiles of low- and high-dose rituximab for MC. Low-dose rituximab yielded

Table 4

Baseline characteristics of patients treated with high-dose rituximab for mixed cryoglobulinemia; data selected from a systematic review of the literature.

\begin{tabular}{|c|c|c|c|c|c|c|c|c|c|c|}
\hline \multirow[t]{2}{*}{ Author [Ref.] } & \multirow[t]{2}{*}{$\mathrm{N}$ of patients } & \multirow[t]{2}{*}{ Age mean } & \multicolumn{3}{|c|}{ Rituximab dosage } & \multirow[t]{2}{*}{ Purpura } & \multirow[t]{2}{*}{ Ulcers } & \multirow[t]{2}{*}{ Neuropathy } & \multirow[t]{2}{*}{ Kidney disease } & \multirow[t]{2}{*}{ Arthralgia } \\
\hline & & & $1000 \mathrm{mg} \times 2$ & $375 \mathrm{mg} / \mathrm{m}^{2} \times 4$ & $375 \mathrm{mg} / \mathrm{m}^{2} \times 6$ & & & & & \\
\hline Cabibbo [24] & 2 & 65 & & 2 & & 2 & & 2 & & \\
\hline Cavallo [21] & 13 & 65 & & & 13 & & & 13 & & \\
\hline Cervetti [16] & 4 & na & & 4 & & 4 & & & & 4 \\
\hline De Vita [18] & 28 & na & & 21 & 7 & 19 & 8 & 13 & 8 & 6 \\
\hline De Vita $[29]^{\mathrm{a}}$ & 28 & 63 & 28 & & & & 5 & 16 & 7 & \\
\hline De Vita [29] ${ }^{\mathrm{a}}$ & 23 & na & 23 & & & & 2 & 13 & 8 & \\
\hline Ferri [27] & 87 & 62 & 18 & 59 & 10 & 51 & 24 & 69 & 38 & \\
\hline Gragnani [28] & 21 & 65 & & 21 & & 19 & 3 & 19 & 5 & 18 \\
\hline Petrarca [19] & 2 & 62 & & 2 & & 2 & 1 & 2 & 2 & 2 \\
\hline Petrarca [25] & 19 & 63 & & 19 & & 17 & 3 & 18 & 5 & 15 \\
\hline Quartuccio [17] & 5 & 57 & & 5 & & 4 & & 2 & 5 & 1 \\
\hline Quartuccio [26] & 5 & 57 & & 5 & & 4 & 1 & 5 & & 2 \\
\hline Roccatello [15] & 6 & 64 & & & 6 & 4 & 1 & 5 & 6 & 6 \\
\hline Saadoun [20] & 21 & 53 & & 21 & & 17 & 3 & 12 & 9 & 13 \\
\hline Sansonno [14] & 20 & 58 & & 20 & & 16 & 7 & 11 & 1 & 20 \\
\hline Senè [22] & 22 & 57 & 4 & 18 & & 17 & & 19 & 10 & \\
\hline Sneller [30] & 12 & 53 & & 12 & & 12 & 4 & 9 & 4 & 7 \\
\hline Stasi [31] & 14 & 60 & 14 & & & 11 & 1 & 7 & 2 & 13 \\
\hline Terrier [23] & 12 & 57 & & 12 & & 8 & & 6 & 4 & 6 \\
\hline Zaja [13] & 15 & 64 & & 15 & & 12 & 5 & 7 & 2 & 4 \\
\hline Total (\%) & 359 & & 87 & 236 & 36 & 219 & 68 & 248 & 116 & 117 \\
\hline
\end{tabular}

${ }^{a}$ In this randomized study, patients treated with rituximab as first line therapy and control patients treated with rituximab after failure of conventional treatment were analyzed as separate groups. Blank cases denote no patients. na, not available. 
an overall (complete plus partial) clinical response of vasculitis $81 \%$, a figure not significantly different from the $86 \%$ that we calculated from data reported in high-dose studies. The laboratory response rates were also similar in low- and high-dose studies. Supplementary Fig. 2 provides detailed information on the clinical and laboratory response rates and confidence intervals in the high-dose studies from which the cumulative data were retrieved.

Fig. 2 illustrates the responses of single vasculitis manifestations in our study and in those studies on high-dose rituximab in which these data were detailed [13-19,21,24-30]. The response rates of skin ulcers, kidney disease and arthralgia were very similar in low- and high-dose trials; purpura responded somewhat worse $(35 / 45,77 \%$, vs $178 / 210$, $85 \%$ ) and peripheral neuropathy somewhat better $(40 / 45,91 \%$, vs $187 / 250,75 \%$ ) in our low-dose compared to high-dose studies, but these differences were not statistically significant.

The proportion of patients who relapsed after clinical response was $41 \%$ in our study and $32 \%$ in studies with high dose rituximab, a difference not statistically significant (Table 2 ). Six studies $[13,14,17$, $24,29,30]$ provided data from 84 patients detailed enough for constructing a Kaplan-Meier curve (Fig. 1). The median time to relapse was 7 months (range 4-12), whereas in our study the median time was 6 (range 4-12), a difference not statistically significant ( $\mathrm{p}=0.67$ ).

Finally, the rate of adverse events could be compared in 371 patients from studies using high-dose rituximab [13-15,17-19,21-27,29,30] and in the 52 patients from our trial (Table 2). Studies with high-dose rituximab displayed a trend to an increased frequency of adverse events ( $19.9 \%$ vs $11.5 \%$ in our study), although this difference failed to reach statistical significance (Table 2).

\section{Discussion}

After more than 15 years of experience with rituximab for the treatment of a number of immunological disorders, drug dosages and therapeutic schemes in different disease contexts are still empirical, and dose/benefit studies are relatively scarce [41,47-51]. A large number of studies demonstrated that rituximab is highly efficacious and safe for the treatment of HCV-associated MC. Drug dosages most commonly used were $375 \mathrm{mg} / \mathrm{m}^{2}$ given 4 times, as for the treatment of B-cell neoplasia, and the so-called "rheumatoid arthritis protocol" of $1000 \mathrm{mg}$ given twice.

In this study, we conducted a phase 2 single-arm, two-stage trial to address the issue of whether a dosage of rituximab lower than those commonly used may be equally effective in MC. Obviously, a trial of

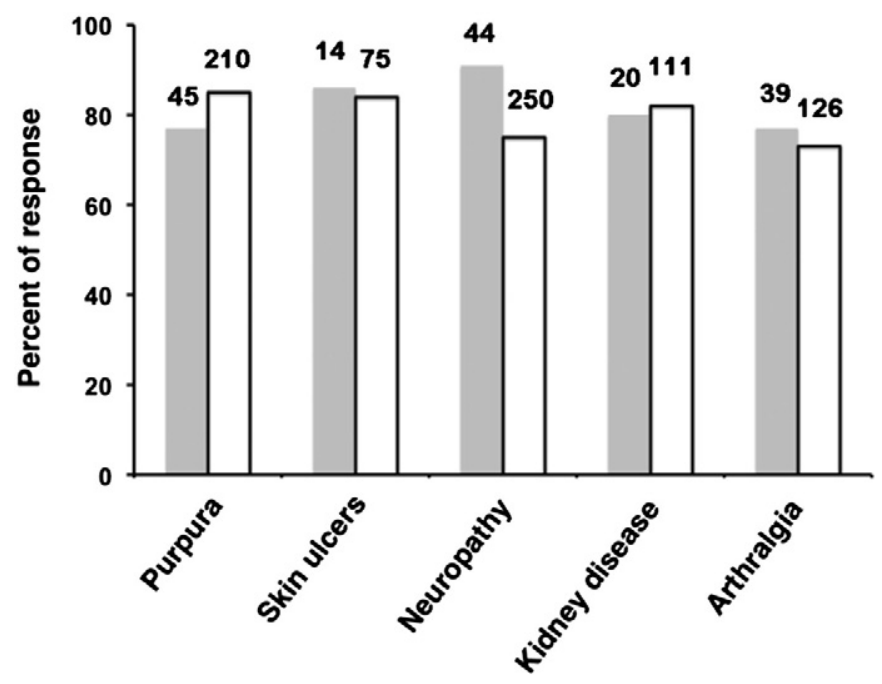

Fig. 2. Response of single vasculitis manifestations to low-dose (gray columns) or highdose (open columns) rituximab. Data illustrate the percentage of responders and the number of evaluable patients for each vasculitis manifestation. equivalence or non-inferiority would be optimal for this purpose but, based on the literature data and on our preliminary results [43], it would demand the enrolment of such a large number of patients to make it unfeasible in a rare disorder such as MC. Thus, we choose a single-arm design with a 52-patients size and a 0.85 statistical power.

We performed a systematic review of the literature collecting all available data from studies using rituximab at standard dosages for MC treatment for a comparison with our results. The availability of only two randomized controlled trials precluded, however, a metaanalysis.

Concerning the comparison of the response rates in our study and in literature reports, it is important to note that previous studies were very heterogeneous, particularly as to method and timing of efficacy assessment and to the use of a validated scoring system, such as the BVAS, which was exploited only by two randomized controlled trials [29,30]. Thus, for studies reporting patients' data at different time-points in sufficient detail we could calculate a BVAS for a direct comparison with the present study, whereas for the other studies we adopted the definition of response provided by the authors. While dutifully taking into account these limitations, low dose rituximab appeared to yield a clinical response rate of $81 \%$, a figure not significantly different from the overall $86 \%$ response rate obtained with higher dosages. The analysis of the response of single organ manifestations may be less biased by different methods of assessment; thus, also by this approach the response of vasculitis appeared to be very similar using low-dose or high-dose rituximab.

Among the 19 selected studies on high-dose rituximab for MC, six $[13,14,17,24,29,30]$ provided detailed data useful for comparing the 12-month relapse rate and the time-to-relapse. The relapse rate was somewhat higher, and the time-to-relapse was somewhat shorter in patients treated with low-dose rather than high-dose rituximab (41\% and 6 months vs $32 \%$ and 7 months, respectively); however, these differences did not reach statistical significance. In an extended phase of our trial, six relapsers received a second course of low-dose rituximab, which led to sustained remission in all except one. Thus, even if assuming as real a $20 \%$ higher relapse rate using low-dose rituximab, retreatment of relapsers with the same dosage would remain costeffective compared to treatment and retreatment with high-dose regimens [29,30].

Concerning laboratory response, we had a similar complete response rate (disappearance of cryoglobulins) compared to high-dose studies, whereas partial responses ( $>50 \%$ decrease of cryocrit) were somewhat inferior. The latter difference could be related in part to the less stringent definition of partial response in some studies $[13,16]$, and to remarkably lower baseline cryocrit levels reported in other studies [25].

Adverse events tended to be less frequent in our trial than in highdose studies, although the difference failed to reach statistical significance. Sène et al. [22] reported a high rate of severe adverse events after high-dose treatment of patients with high cryocrit values, and suggested a dose-dependency of rituximab side effects in these patients. Thus, more data are needed to confirm that low-dose rituximab might be safer in patients with mixed cryoglobulinemia.

We recorded six deaths (11.5\%) throughout the study, none of which was related to rituximab treatment. Previous studies with high-dose rituximab reported similar high rates of treatment-unrelated deaths of $10.5 \%$ [29], 9\% [23] and 13\% [52], mostly associated, as in the case of our study, with older age and comorbidities.

Our phase 2 study provides evidence that rituximab treatment for mixed cryoglobulinemia at the reduced dosage of $250 \mathrm{mg} / \mathrm{m}^{2} \times 2$ has similar effectiveness than at higher dosages. These results may help to optimize rituximab therapy for patients with HCV-associated mixed cryoglobulinemia who fail to respond to antiviral therapy [9]. The recently available DAA agents promise to dramatically reduce the proportion of patients who need salvage therapy with rituximab [10-12]. However, low-dose rituximab in combination with DAA is likely to be 
of value for treating severe forms of cryoglobulinemic vasculitis [23,53], and may provide a cost/effective and possibly safer strategy for treating the $10-30 \%$ of mixed cryoglobulinemia cases that are not associated with HCV infection [52].

\section{Take-home messages}

- Rituximab at the low dosage of $250 \mathrm{mg} / \mathrm{m}^{2} \times 2$ is as effective as the higher dosage of $375 \mathrm{mg} / \mathrm{m}^{2} \times 4$ for treating HCV-associated mixed cryoglobulinemia

- The low-dose regimen may improve the cost/benefit profile of rituximab therapy for mixed cryoglobulinemia.

\section{Disclosures}

The authors disclose any actual or potential conflict of interest including any financial, personal or other relationships with other people or organizations within three years of beginning the submitted work that could inappropriately influence, or be perceived to influence, their work.

\section{Acknowledgments}

This work was supported by grant FARM6KMZFY from the Agenzia Italiana per il Farmaco (AIFA). Marcella Visentini was supported by Fondazione Roma (Prot287/AI), Rome, Italy.

Laura Gragnani was supported by "Fondazione Umberto Veronesi", Alessia Piluso was supported by "FIRE", Elisa Fognani was supported by AIRC.

\section{Appendix A. Supplementary data}

Supplementary data to this article can be found online at http://dx. doi.org/10.1016/j.autrev.2015.05.013.

\section{References}

[1] Cacoub P, Comarmond C, Domont F, Savey L, Saadoun D. Cryoglobulinemia vasculitis. Am J Med Mar 302015 [Epub ahead of print].

[2] Monti G, Saccardo F, Castelnovo L, Novati P, Sollima S, Riva A, et al. Prevalence of mixed cryoglobulinaemia syndrome and circulating cryoglobulins in a populationbased survey: the Origgio study. Autoimmun Rev 2014;13:609-14.

[3] Visentini M, Conti V, Cristofoletti C, Lazzeri C, Marrapodi R, Russo G, et al. Clonal expansion and functional exhaustion of monoclonal marginal zone B cells in mixed cryoglobulinemia: the yin and yang of HCV-driven lymphoproliferation and autoimmunity. Autoimmun Rev 2013;12:430-5.

[4] Saadoun D, Suarez F, Lefrere F, Valensi F, Mariette X, Aouba A, et al. Splenic lymphoma with villous lymphocytes, associated with type II cryoglobulinemia and HCV infection: a new entity? Blood 2005;105:74-6.

[5] Casato M, Mecucci C, Agnello V, Fiorilli M, Knight GB, Matteucci C, et al. Regression of lymphoproliferative disorder after treatment for hepatitis $C$ virus infection in a patient with partial trisomy $3, \mathrm{Bcl}-2$ overexpression, and type II cryoglobulinemia. Blood 2002;99:2259-61.

[6] Hermine O, Lefrère F, Bronowicki JP, Mariette X, Jondeau K, Eclache-Saudreau V, et al. Regression of splenic lymphoma with villous lymphocytes after treatment of hepatitis C virus infection. N Engl J Med 2002;347:89-94.

[7] Casato M, Saadoun D, Marchetti A, Limal N, Picq C, Pantano P, et al. Central nervous system involvement in hepatitis $C$ virus cryoglobulinemia vasculitis: a multicenter case-control study using magnetic resonance imaging and neuropsychological tests. J Rheumatol 2005;32:484-8.

[8] Pietrogrande M, De Vita S, Zignego AL, Pioltelli P, Sansonno D, Sollima S, et al. Recommendations for the management of mixed cryoglobulinemia syndrome in hepatitis C virus-infected patients. Autoimmun Rev 2011;10:444-54.

[9] Dammacco F, Sansonno D. Therapy for hepatitis C virus-related cryoglobulinemic vasculitis. N Engl J Med 2013;369:1035-45.

[10] Visentini M, Colantuono S, Granata G, de Santis A, Fiorilli M, Casato M. The case for cost-effectively treating cryoglobulinemic vasculitis with interferon-free antihepatitis C virus therapy. Hepatology Nov 7 2014. http://dx.doi.org/10.1002/hep. 27600 [Epub ahead of print].

[11] Hagan LM, Sulkowski MS, Schinazi RF. Cost analysis of sofosbuvir/ribavirin versus sofosbuvir/simeprevir for genotype 1 hepatitis C virus in interferon-ineligible/ intolerant individuals. Hepatology 2014;60:37-45

[12] Bunchorntavakul C, Maneerattanaporn M, Chavalitdhamrong D. Management of patients with hepatitis C infection and renal disease. World J Hepatol 2015;7: 213-25.
[13] Zaja F, De Vita S, Mazzaro C, Sacco S, Damiani D, De Marchi G, et al. Efficacy and safety of rituximab in type II mixed cryoglobulinemia. Blood 2003;101:3827-34.

[14] Sansonno D, De Re V, Lauletta G, Tucci FA, Boiocchi M, Dammacco F. Monoclonal antibody treatment of mixed cryoglobulinemia resistant to interferon alpha with an anti-CD20. Blood 2003;101:3818-23.

[15] Roccatello D, Baldovino S, Rossi D, Mansouri M, Naretto C, Gennaro M, et al. Longterm effects of anti-CD20 monoclonal antibody treatment of cryoglobulinaemic glomerulonephritis. Nephrol Dial Transplant 2004;19:3054-61.

[16] Cervetti G, Mechelli S, Riccioni R, Galimberti S, Caracciolo F, Petrini M. High efficacy of rituximab in indolent HCV-related lymphoproliferative disorders associated with systemic autoimmune diseases. Clin Exp Rheumatol 2005;23:877-80.

[17] Quartuccio L, Soardo G, Romano G, Zaja F, Scott CA, De Marchi G, et al. Rituximab treatment for glomerulonephritis in HCV-associated mixed cryoglobulinaemia: efficacy and safety in the absence of steroids. Rheumatology (Oxford) 2006;45:842-6.

[18] De Vita S, Quartuccio L, Fabris M. Rituximab in mixed cryoglobulinemia: increased experience and perspectives. Dig Liver Dis 2007;39(Suppl. 1):S122-8.

[19] Petrarca A, Rigacci L, Monti M, Giannini C, Bernardi F, Caini P, et al. Improvement in liver cirrhosis after treatment of HCV-related mixed cryoglobulinemia with rituximab. Dig Liver Dis 2007;39(Suppl. 1):S129-33.

[20] Saadoun D, Rosenzwajg M, Landau D, Piette JC, Klatzmann D, Cacoub P. Restoration of peripheral immune homeostasis after rituximab in mixed cryoglobulinemia vasculitis. Blood 2008;111:5334-41.

[21] Cavallo R, Roccatello D, Menegatti E, Naretto C, Napoli F, Baldovino S. Rituximab in cryoglobulinemic peripheral neuropathy. J Neurol 2009;256:1076-82.

[22] Sène D, Ghillani-Dalbin P, Amoura Z, Musset L, Cacoub P. Rituximab may form a complex with IgMkappa mixed cryoglobulin and induce severe systemic reactions in patients with hepatitis C virus-induced vasculitis. Arthritis Rheum 2009;60: 3848-55.

[23] Terrier B, Saadoun D, Sène D, Sellam J, Pérard L, Coppéré B, et al. Efficacy and tolerability of rituximab with or without PEGylated interferon alfa-2b plus ribavirin in severe hepatitis C virus-related vasculitis: a long-term followup study of thirtytwo patients. Arthritis Rheum 2009;60:2531-40.

[24] Cabibbo S, Antolino A, Garozzo G, Manenti GO, Bonomo P. Clinical improvement induced by rituximab in two cases of type II mixed cryoglobulinaemia syndrome unresponsive to conventional treatments. Blood Transfus 2010;8:196-8.

[25] Petrarca A, Rigacci L, Caini P, Colagrande S, Romagnoli P, Vizzutti F, et al. Safety and efficacy of rituximab in patients with hepatitis $C$ virus-related mixed cryoglobulinemia and severe liver disease. Blood 2010;116:335-42.

[26] Quartuccio L, Petrarca A, Mansutti E, Pieroni S, Calcabrini L, Avellini C, et al. Efficacy of rituximab in severe and mild abdominal vasculitis in the course of mixed cryoglobulinemia. Clin Exp Rheumatol 2010;28(1 Suppl. 57):84-7.

[27] Ferri C, Cacoub P, Mazzaro C, Roccatello D, Scaini P, Sebastiani M, et al. Treatment with rituximab in patients with mixed cryoglobulinemia syndrome: results of multicenter cohort study and review of the literature. Autoimmun Rev 2011;11: 48-55.

[28] Gragnani L, Piluso A, Giannini C, Caini P, Fognani E, Monti M, et al. Genetic determinants in hepatitis $C$ virus-associated mixed cryoglobulinemia: role of polymorphic variants of BAFF promoter and Fc $\gamma$ receptors. Arthritis Rheum 2011;63:1446-51.

[29] De Vita S, Quartuccio L, Isola M, Mazzaro C, Scaini P, Lenzi M, et al. A randomized controlled trial of rituximab for the treatment of severe cryoglobulinemic vasculitis. Arthritis Rheum 2012;64:843-53.

[30] Sneller MC, Hu Z, Langford CA. A randomized controlled trial of rituximab following failure of antiviral therapy for hepatitis C virus-associated cryoglobulinemic vasculitis. Arthritis Rheum 2012;64:835-42.

[31] Stasi C, Triboli E, Arena U, Urraro T, Petrarca A, Gragnani L, et al. Assessment of liver stiffness in patients with HCV and mixed cryoglobulinemia undergoing rituximab treatment. J Transl Med 2014;12:21.

[32] Tak PP, Rigby WF, Rubbert-Roth A, Peterfy CG, van Vollenhoven RF, Stohl W, et al. Inhibition of joint damage and improved clinical outcomes with rituximab plus methotrexate in early active rheumatoid arthritis: the IMAGE trial. Ann Rheum Dis 2011;70:39-46.

[33] Emery P, Fleischmann R, Filipowicz-Sosnowska A, Schechtman J, Szczepanski L, Kavanaugh A, et al. For the DANCER Study Group. The efficacy and safety of rituximab in patients with active rheumatoid arthritis despite methotrexate treatment: results of a phase IIb randomized, double-blind, placebo-controlled, dose-ranging trial. Arthritis Rheum 2006;54:1390-400.

[34] Emery P, Deodhar A, Rigby WF, Isaacs JD, Combe B, Racewicz AJ, et al. Efficacy and safety of different doses and retreatment of rituximab: a randomised, placebocontrolled trial in patients who are biological naive with active rheumatoid arthritis and an inadequate response to methotrexate (Study Evaluating Rituximab's Efficacy in MTX iNadequate rEsponders (SERENE)). Ann Rheum Dis 2010;69: 1629-35.

[35] Looney RJ, Anolik JH, Campbell D, Felgar RE, Young F, Arend LJ, et al. B cell depletion as a novel treatment for systemic lupus erythematosus: a phase I/II dose-escalation trial of rituximab. Arthritis Rheum 2004:50:2580-9.

[36] Galarza-Maldonado C, Kourilovitch MR, Molineros JE, Cardiel MH, Zurita L, Soroka NF, et al. The administration of low doses of rituximab followed by hydroxychloroquine, prednisone and low doses of mycophenolate mofetil is an effective therapy in Latin American patients with active systemic lupus erythematosus. Autoimmun Rev 2010;10:108-11.

[37] Barcellini W, Zaja F, Zaninoni A, Imperiali FG, Battista ML, Di Bona E, et al. Low-dose rituximab in adult patients with idiopathic autoimmune hemolytic anemia: clinical efficacy and biologic studies. Blood 2012;119:3691-7.

[38] Zaja F, Vianelli N, Volpetti S, Battista ML, Defina M, Palmieri S, et al. Low-dose rituximab in adult patients with primary immune thrombocytopenia. Eur J Haematol 2010;85:329-34. 
[39] Horváth B, Huizinga J, Pas HH, Mulder AB, Jonkman MF. Low-dose rituximab is effective in pemphigus. Br J Dermatol 2012;166:405-12.

[40] Iorio R, Damato V, Alboini PE, Evoli A. Efficacy and safety of rituximab for myasthenia gravis: a systematic review and meta-analysis. J Neurol 2015;262:1115-9.

[41] Bredemeier M, de Oliveira FK, Rocha CM. Low- versus high-dose rituximab for rheumatoid arthritis: a systematic review and meta-analysis. Arthritis Care Res 2014;66:228-35.

[42] Visentini M, Granata M, Veneziano ML, Borghese F, Carlesimo M, Pimpinelli F, et al Efficacy of low-dose rituximab for mixed cryoglobulinemia. Clin Immunol 2007;125: 30-3.

[43] Visentini M, Ludovisi S, Petrarca A, Pulvirenti F, Zaramella M, Monti M, et al. A phase II, single-arm multicenter study of low-dose rituximab for refractory mixed cryoglobulinemia secondary to hepatitis C virus infection. Autoimmun Rev 2011; 10:714-9.

[44] Damoiseaux J. The diagnosis and classification of the cryoglobulinemic syndrome. Autoimmun Rev 2014;13:359-62.

[45] Bianchettin G, Bonaccini C, Oliva R, Tramontano A, Cividini A, Casato M, et al. Analysis of hepatitis $C$ virus hypervariable region 1 sequence from cryoglobulinemic patients and associated controls. J Virol 2007;81:4564-71.

[46] Lutt JR, Pisculli ML, Weinblatt ME, Deodhar A, Winthrop KL. Severe nontuberculous mycobacterial infection in 2 patients receiving rituximab for refractory myositis. J Rheumatol 2008;35:1683-5.
[47] Buch MH, Smolen JS, Betteridge N, Breedveld FC, Burmester G, Dörner T, et al. Updated consensus statement on the use of rituximab in patients with rheumatoid arthritis. Ann Rheum Dis 2011;70:909-20.

[48] Golay J, Semenzato G, Rambaldi A, Foà R, Gaidano G, Gamba E, et al. Lessons for the clinic from rituximab pharmacokinetics and pharmacodynamics. MAbs 2013;5:826-37.

[49] van Vollenhoven RF. More or less rituximab? Biology and clinic, regulators and researchers. Arthritis Rheum 2011;63:594-6.

[50] Vital EM, Rawstron AC. Dass S, Henshaw K, Madden J, Emery P, et al. Reduced-dose rituximab in rheumatoid arthritis: efficacy depends on degree of B cell depletion. Arthritis Rheum 2011;63:603-8.

[51] Kattah AG, Fervenza FC, Roccatello D. Rituximab-based novel strategies for the treatment of immune-mediated glomerular diseases. Autoimmun Rev 2013;12:854-9.

[52] Terrier B, Launay D, Kaplanski G, Hot A, Larroche C, Cathébras P, et al. Safety and efficacy of rituximab in nonviral cryoglobulinemia vasculitis: data from the French Autoimmunity and Rituximab registry. Arthritis Care Res 2010;62:1787-95.

[53] Urraro T, Gragnani L, Piluso A, Fabbrizzi A, Monti M, Fognani E, et al. Combined treatment with antiviral therapy and rituximab in patients with mixed cryoglobulinemia: review of the literature and report of a case using direct antiviral agents-based antihepatitis C virus therapy. Case Rep Immunol 2015;2015:816424 [Epub 2015 Mar 1].

\section{Small molecules and vaccines: should we be careful?}

It is well know that patients with rheumatoid arthritis (RA) have an increased risk of developing infections. For these reason, the European League Against Rheumatism (EULAR) has developed a number of recommendations regarding the management of vaccination in RA patients. One of the strongest recommendation suggest to consider anti-anti-influenza and pneumococcal vaccinations in all patients. However, the concurrent treatment may reduce the effect of the vaccination as it was observed for the anti-CD20 agent Rituximab. Moreover, several new drugs are currently under investigation in the disease, including that group so-called small molecules. Tofacitinib is an oral Janus kinase (JAK) inhibitor for the treatment of RA.

Recently, Winthrop KL, et al. examined the effect of tofacitinib on pneumococcal and influenza vaccine responses in rheumatoid arthritis (Winthrop KL, et al. Ann Rheum Dis. 2015 Mar 20). Two studies were conducted aiming at 1) address the effect of the anti-JAK treatment on influenza and pneumococcal vaccination in tofacitinib-naive RA patients, 2) whether patients with RA receiving tofacitinib need to stop therapy while giving vaccinations.

Fewer tofacitinib patients (45.1\%) developed satisfactory pneumococcal responses versus placebo (68.4\%), and pneumococcal titres were lower with tofacitinib. Methotrexate seems partly co-responsible of this impaired effect. Also, fewer tofacitinib patients (76.5\%) developed protective influenza titres ( $\geq 1: 40$ in two or more of three antigens) versus placebo (91.8\%).

In the second study, there were not statistically significant differences in satisfactory responses to PPSV-23 and influenza among patients who continued or withdrawn tofacitinib treatment. Thus, physicians should be aware that RA patients starting tofacitinib have a diminished responsiveness to pneumococcal PPSV-23 and, even if at a minor extent, to influenza vaccinations. Drug discontinuation has a minor impact on the achievement of a satisfactory response to vaccines. This is also interesting given the mechanism of action of tofacitinib, possibly suggesting an effect on B cell responses. This evidence finds confirmation in an in vitro study by Wang et al. (Wang SP et al. Ann Rheum Dis. 2014 Dec;73(12):2213-5).

\section{Carlo Perricone, M.D.}

